\title{
Mandatory HIV screening for emergency physicians in Ontario: protecting the public or alarming them?
}

\author{
Marco L.A. Sivilotti, MD, MSc
}

If you practice emergency medicine in Ontario, you probably did not realize that you now need to be tested annually for human immunodeficiency virus (HIV) and hepatitis C. With little fanfare and citing "the best available evidence," policy creep has resulted in Ontario becoming one of the few jurisdictions in the free world to implement de facto mandatory screening for HIV based on occupation. This testing is misguided and harmful, and likely violates our Charter rights. The College of Physicians and Surgeons of Ontario believes that other jurisdictions are watching closely, which is why physicians everywhere should take notice of this important precedent justified on the basis of the College's motto Protecting the public.

Until recently, the College's policy requested physicians to self-identify whether they performed "exposureprone procedures" and, if so, to be tested for hepatitis B, hepatitis C, and HIV. ${ }^{1}$ Exposure-prone procedures were defined based on a Health Canada consensus conference as those involving "digital palpation of a needle tip in a body cavity...or highly confined anatomic sites (e.g., during major abdominal, cardiothoracic, vaginal, and/or orthopedic operations), or repair of major traumatic injuries, or manipulation, cutting or removal of any oral or perioral tissue..." This definition was developed empirically to deal with the occupational health issue of work restrictions for physicians infected with bloodborne pathogens. Most surgeons who regularly operate within the mouth, chest, abdomen, and pelvis acknowledged this component of their practice and agreed to one-time testing. Most emergency physicians, on the other hand, answered "no" to the question, "In your practice, do you perform exposure-prone procedures...?" presumably because "rarely if ever," "only if no more experienced physician were available," and "only if the patient were moribund" were not listed as possible answers.

In May 2012, the policy was reviewed and updated. ${ }^{3}$ In addition to moving to annual testing because "busy physicians were not finding the time to be tested," the policy now contained an appendix listing specific procedures considered exposure prone. This somewhat arbitrary list of procedures was taken verbatim from a table in an updated consensus guideline developed by the Society for Healthcare Epidemiology of America (SHEA) to manage health care workers already infected with hepatitis B, hepatitis C, or HIV.5 Of particular interest to emergency physicians, "nonelective procedures in the emergency department, including open resuscitation efforts, deep suturing to arrest hemorrhage, and internal cardiac massage" and "interactions with violent patients or patients experiencing an epileptic seizure," were now on the proscribed list of procedures deemed exposure prone. Although many emergency physicians have the good fortune of never needing to do a resuscitative thoracotomy, it is a different matter to tell the College that one would never do so under any circumstances. Even if one would never contemplate doing a perimortem cesarean section, I have yet to find an emergency physician who does not interact with violent patients. Yet by burying the change in an appendix, few noticed the change.

Broader yet, when one reads the policy's $\mathrm{FAQ}^{6}$ and the SHEA guideline ${ }^{5}$ carefully, is the footnote that phlebotomy, when performed in an emergency, is also considered exposure prone by the College. Now every

From the Departments of Emergency Medicine and Biomedical and Molecular Sciences, Queen's University, Kingston, ON.

Correspondence to: Dr. Marco Sivilotti, Department of Emergency Medicine, Queen's University, 76 Stuart Street, Kingston, ON K7L 2V7; marco. sivilotti@queensu.ca.

This article has been peer reviewed.

(C) Canadian Association of Emergency Physicians 
physician who might do a femoral stick or start a peripheral line in a sick patient requires annual testingnot after doing such a procedure but only because they might do it. Even assisting at any of the procedures, according to the policy, requires annual testing. For physicians who practice emergency medicine, the formalization of the SHEA suggestions into policy amounts to imposing mandatory testing on all of us.

But what is the "best evidence available" behind this desire to be absolutely certain that Ontario patients never be allowed to contract HIV from an emergency physician trying to save their life: Level III quality or opinion of respected authorities. ${ }^{5}$ The document does an excellent job of summarizing the world literature of probable physician-to-patient transmission of HIV: two cases. ${ }^{7,8}$ Neither involved emergency physicians or circumstances even remotely related to our practice. In almost every instance of "looking back" on an HIVpositive surgeon's practice, no new cases have been identified among $>30,000$ potential exposures..$^{9,10}$ Although an addicted anesthesiologist might share opioids and, rarely, hepatitis $\mathrm{C}$ with his or her patients, the available evidence suggests that the risk of nosocomial transmission of HIV approaches zero. There is certainly no science behind the expanded list of exposure-prone procedures, which was never intended to be the basis for a mass screening program.

But we already know that HIV does not magically transduce across the usual physician-patient relationship. We know this because we wallow in body fluids (including sweat) every working day. We are also the front line, counseling patients and colleagues daily on the risks of infection. We interpret the available science to discuss rabies prophylaxis whenever someone finds a bat in the house, tetanus when someone steps on a nail, and sexually transmitted infections when someone mixes drinking and sex. Patients with occupational blood-borne infection exposures come to see us, day and night, fearing the worst. We can often tell them with confidence that it is essentially impossible to contract HIV based on their exposure circumstances because, quite simply, this is not how the virus is transmitted. Even when the exposure is more concerning, the global experience informs us that the risk of provider-topatient transmission is orders of magnitude smaller than patient-to-provider transmission. ${ }^{11}$ When postexposure prophylaxis is futile or the risks outweigh the benefits, we tell that to the patient. And when testing is simply not indicated, we are prepared to explain why. One can estimate that the number of Ontario emergency physicians needed to test to prevent one case of nosocomial HIV exceeds 1 billion (95\% CI 300 million to infinity)—futility incarnate. Pursuing zero risk is always wasteful, as airport security demonstrates.

Is it so harmful to run a few extra tests and perhaps detect a few occult cases of hepatitis C? Here the argument grows more complex, but, at its heart, it deals with the contract we have with our future patients and the role of the profession to combat medieval stereotypes surrounding contagion. Emergency physicians acknowledge the tremendous privilege they enjoy: when people are most ill, injured, or afraid, they come to us. In return for their trust, we agree to come to work every day whether the World Health Organization announces another severe acute respiratory syndrome (SARS)-like coronavirus on the loose or that the next global pandemic is upon us. We gown and glove for the alphabet soup of vancomycin-resistant Enterococcus/ methicillin-resistant Staphylococcus aureus/Clostridum difficile precautions and try to restore some humanity and dignity into that encounter. We even occasionally abbreviate universal precautions (now "routine practices" in infection control newspeak) for the drunk and belligerent multiple stab wound victim bleeding to death. We do it in part because our rational mind keeps the risks in perspective. Importantly, we do not require, nor can we demand, mandatory HIV screening of our patients in the absence of exposure because we recognized long ago that such a policy would simply stoke the flames of fear and ignorance that continue to surround infectious diseases such as HIV. The message that we are a danger to our patients if we do not get tested does not reassure the public. It distorts the risks of the health care encounter, promotes a climate of fear, and thereby becomes harmful (Figure 1). Threatening noncompliant physicians with disciplinary action for professional misconduct ${ }^{6}$ may appease the scaremongers, but it hurts us all. The SHEA guidelines themselves recommend against mandatory screening (recommendation 12; level A-III), ${ }^{5}$ a detail that was missed in the rush to protect patients from "unacceptable risks."

Individual liberties can be curbed during public health emergencies. But such circumstances are extraordinary and need to be justifiable and as temporary as possible. Where is the public health emergency here? Approximately 2,500 Canadians became infected with HIV last year-not one of them from "bleedback" from their treating physician. The extraordinary step 


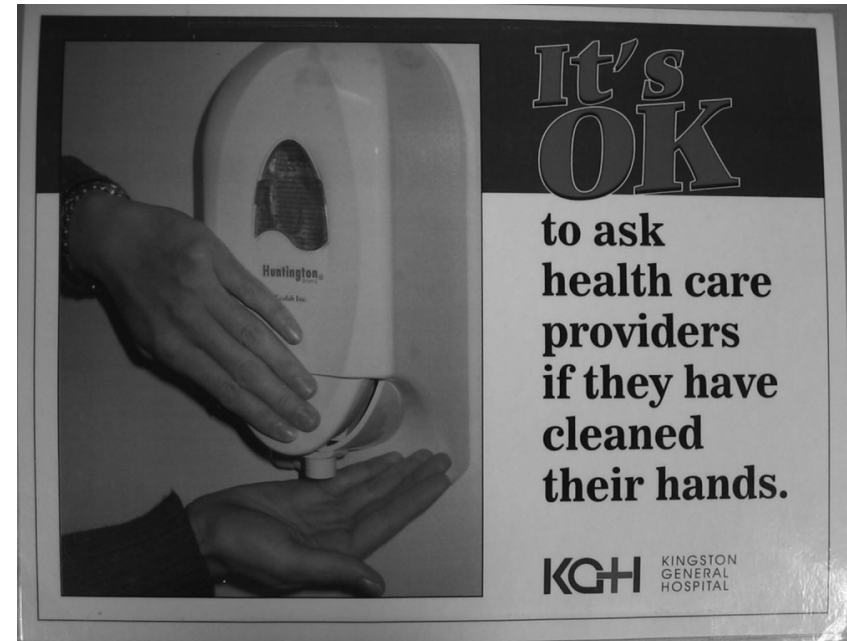

Figure 1. ... and have been tested for HIV.

of mandatory screening will have no impact on the global effort to curb the spread of this disease.

The College should continue to advocate for Medice cura te ipsum ("Physician, heal thyself"), and physicians do have an ethical obligation to be in the best possible physical and mental health for the good of their patients. Some physicians may even want to know their own HIV status with certainty and can make an informed choice to get tested. But mandatory testing of low-risk physicians is alarmist and undermines the authority of the College and the scientific foundation of the profession.

Competing interests: None declared.

\section{REFERENCES}

1. College of Physicians and Surgeons of Ontario. CPSO Policy Statement \#6-05: Physicians with blood borne pathogens.
Available at: http://www.cpso.on.ca/uploadedfiles/policies/ policies/policyitems/bloodborne2005(1).pdf (accessed February 20,2013$)$.

2. Health Canada. Proceedings of the Consensus Conference on Infected Health Care Worker Risk for transmission of bloodborne pathogens. Can Commun Dis Rep 1998;24 Suppl $4: 1-25$.

3. College of Physicians and Surgeons of Ontario. CPSO Policy Statement \#3-12: Blood borne pathogens. Available at: http:// www.cpso.on.ca/uploadedFiles/policies/policies/policyitems/ Blood-Borne-Pathogens_Policy.pdf (accessed February 20, 2013).

4. Policy matters: blood borne pathogens. CPSO Dialogue 2012; $8(2): 19-20$

5. Hendeson DK, Dembry L, Fishman NO, et al. SHEA guidelines for management of healthcare workers who are infected with hepatitis B virus, hepatitis C virus, and/or human immunodeficiency virus. Infect Control Hosp Epidemiol 2010;31:203-2, doi:10.1086/650298.

6. College of Physicians and Surgeons of Ontario. Physicians with blood borne pathogens FAQs. Mandatory questions for registration renewal frequently asked questions 2012. Available at: http://www.cpso.on.ca/members/membership/default.aspx? id=4926 (accessed February 20, 2013).

7. Lot F, Séguier J-C, Fégueux S, et al. Probable transmission of HIV from an orthopaedic surgeon to a patient in France. Ann Intern Med 1999;130:1-6.

8. Bosch X. Second case of doctor-to-patient HIV transmission. Lancet Infect Dis 2003;3:261, doi:10.1016/S14733099(03)00622-4.

9. Salkeld L, McGeehan S. HIV testing of health care workers in England-a flawed policy. 7 Health Serv Res Pol 2010;15 Suppl 2:62-7, doi:10.1258/jhsrp.2009.009095.

10. Robert LM, Chamberland ME, Cleveland JL, et al. Investigations of patients of health care workers infected with HIV. Ann Intern Med 1995;122:653-7.

11. Health Protection Agency. Occupational transmission of HIV summary of published reports. March 2005 edition (data to end of December 2002). London: Health Protection Agency; March 2005. Available at: http://www.hpa.org.uk/webc/HPAwebFile/ HPAweb_C/1194947320156 (accessed February 20, 2013). 